\title{
Retrieval analysis of different orthodontic brackets: the applicability of electron microprobe techniques for determining material heterogeneities and corrosive potential
}

\author{
Alexandra loana HOLST ${ }^{1}$, Stefan HOLST ${ }^{2}$, Ursula HIRSCHFELDER ${ }^{3}$, Volker von SECKENDORFF ${ }^{4}$ \\ 1- Dr. Med. Dent., PhD Associate Professor, University Clinic Erlangen, Dental Clinic 3 - Department of Orthodontics, Erlangen, Germany. \\ 2- Dr. Med. Dent., PhD, Associate Professor, University Clinic Erlangen, Dental Clinic 2 - Department of Prosthodontics, Erlangen, Germany. \\ 3- Prof. Dr. Med. Dent., PhD, Professor and Chairman, University Clinic Erlangen, Dental Clinic 3 - Department of Orthodontics, Erlangen, Germany. \\ 4- Dr. Rer. Nat., Research Associate, University Wurzburg, Institute for Geography, Chair for Geodynamics and Geomaterials Research, Wurzburg, Germany.
}

Corresponding address: Dr. Alexandra loana Holst - University Clinic Erlangen - Dental Clinic 3 - Department of Orthodontics - Glückstrasse 11 - 91054 Erlangen - Germany - alexandra.holst@uk-erlangen.de

Received: November 22, 2010 - Modification: August 2, 2011 - Accepted: August 25, 2011

\section{ABSTRACT}

\begin{abstract}
O bjective: The objective of this study was to investigate the applicability of microanalytical methods with high spatial resolution to the characterization of the composition and corrosion behavior of two bracket systems. Material and methods: The surfaces of six nickel-free brackets and six nickel-containing brackets were examined for signs of corrosion and qualitative surface analysis using an electron probe microanalyzer (EPMA), prior to bonding to patient's tooth surfaces and four months after clinical use. The surfaces were characterized qualitatively by secondary electron (SE) images and back scattered electron (BSE) images in both compositional and topographical mode. Qualitative and quantitative wavelength-dispersive analyses were performed for different elements, and by utilizing qualitative analysis the relative concentration of selected elements was mapped two-dimensionally. The absolute concentration of the elements was determined in specially prepared brackets by quantitative analysis using pure element standards for calibration and calculating correction-factors (ZAF). Results: Clear differences were observed between the different bracket types. The nickel-containing stainless steel brackets consist of two separate pieces joined by a brazing alloy. Compositional analysis revealed two different alloy compositions, and reaction zones on both sides of the brazing alloy. The nickel-free bracket was a single piece with only slight variation in element concentration, but had a significantly rougher surface. After clinical use, no corrosive phenomena were detectable with the methods applied. Traces of intraoral wear at the contact areas between the bracket slot and the arch wire were verified. Conclusion: Electron probe microanalysis is a valuable tool for the characterization of element distribution and quantitative analysis for corrosion studies.
\end{abstract}

Key words: Orthodontic bracket. Galvanic corrosion. Electron probe microanalysis. Nickel.

\section{INTRODUCTION}

Concomitant increases in the prevalence of allergic reactions to alloys, predominantly nickel (Ni) and chromium $(\mathrm{Cr})$, have added to the general interest in alloy composition and corrosive phenomena in dentistry. $\mathrm{Ni}$-containing alloys with a $\mathrm{Ni}$ content exceeding 50 wt.-\% are routinely applied in restorative dentistry due to cost-effectiveness and ideal material properties such as strength, elasticity, and hardness ${ }^{18}$. However, unlike highnoble alloys, which exhibit good resistance to corrosion due to their low reactivity as stated by Geurtsen $^{8}$ (2002), Ni-containing alloys are more prone to surface wear ${ }^{16}$.

Corrosion cannot be entirely prevented in the oral cavity, as dental materials and orthodontic appliances are exposed to various biological, 
mechanical, and environmental stresses depending on their material composition, manufacturing process, and microstructure $9,21,26$. Galvanic interaction in orthodontics is most likely to occur between the archwire and the bracket due to friction, as shown by Eliades and Athanasiou ${ }^{6}$ (2002) or can occur within a bracket's own components ${ }^{29}$. While conventional metal brackets contain different stainless steel alloys in the bracket base and tie wings, which are then soldered with silver ( $\mathrm{Ag}), \mathrm{Ni}$, or gold alloys, alternative manufacturing techniques such as metal injection molding are applied in an attempt to minimize corrosive potential. In an in vitro study, Siargos, et al. ${ }^{27}$ (2007) stated that single-component brackets may provide a measurable benefit when compared to conventional brackets, due to uniform elemental distribution. Also external factors such as the interaction of fluoride containing solutions and metals such as titanium are well investigated in dental literature and should not be underestimated when interpreting results ${ }^{4,25}$.

Controversy exists regarding whether the ion release from orthodontic appliances due to corrosion has a localized or systemic effect on patient health. An in vitro study on human cell cultures ${ }^{28}$ has described potential carcinogenic, mutagenic, and cytotoxic effects of metal ions in general, while Tomakidi, et al. ${ }^{24}$ (2000) found no such effects. The amount of ions released from orthodontic appliances in vivo remains unclear.

Hypersensitivity is the most common effect to $\mathrm{Ni}$ and $\mathrm{Cr}$, and is frequently reported in dermatology. In a review, Noble, et al. ${ }^{15}$ (2008) reported on the influence of gender for the prevalence of nickel hypersensitivity which is supported by other research results ${ }^{12}$. With the exception of some isolated case reports on gingival hyperplasia, labial desquamation, angular cheilitis, swelling, and burning sensations of the oral mucosa, a general correlation between the respective ions and hypersensitive reaction has not been substantiated in dentistry ${ }^{23}$. In a review of the literature, House, et al. ${ }^{26}$ (2008) stated that most patients with confirmed $\mathrm{Ni}$ sensitivity show no reaction to intraoral Ni-containing alloys.

There are three ways to investigate metal ion release: in vitro, retrieval (ex-vivo investigation of in-vivo aged samples), and in vivo. In vitro investigations are excellent methods to investigate a specific topic while eliminating interfering side effects. In vitro results can only provide general guidance due to the multi-factorial environmental conditions in the oral cavity, but these studies must be considered because there are few alternatives ${ }^{11}$.

In vivo research lacks obtainable explanatory power, as saliva, blood, and urine samples are always a representation of local effects and general external influences. The greatest challenge of in vivo investigations concerning ion release of alloys is differentiating between ions released through corrosion and ion intake from nutrition. On average, 200 to $300 \mathrm{mg} \mathrm{Ni}$ and $280 \mathrm{mg} \mathrm{Cr}$ are consumed by a person per day ${ }^{11}$. In vivo investigations using saliva samples to determine the ionic release of alloys found $\mathrm{Cr}$ and $\mathrm{Ni}$ concentrations far below that of normal dietary intake ${ }^{3}$.

An alternative investigative method is retrieval studies that try to combine in vivo and in vitro methodologies. As opposed to medical disciplines such as orthopedics, where ex-vivo investigations on hip replacements can only be performed if an implant fails, orthodontic brackets and wires offer the possibility of easy retrieval. Before initiating time- and cost-intensive research projects, analytical methods must be validated in pilot investigations. While several ex-vivo studies have been performed on orthodontic archwires, no such studies are available for different bracket systems. To specify and measure the amount of ion release (especially the release of $\mathrm{Ni}$ and $\mathrm{Cr}$ ions) during orthodontic treatment, highly sensitive analytical methods are needed.

The aim of the present pilot investigation was to assess whether surface changes like ionic reduction occur on alloy surfaces during clinical use before extensive clinical in vivo investigations are initiated. In a similar study, Eliades, et al. ${ }^{7}$ (2004) investigated Ni release from two different orthodontic archwires (stainless steel and NickelTitanium [Ni-Ti] wires) retrieved after an intra-oral service period between 1.5 and 12 months and compared them with as-received wires. Scanning electron microscopy (SEM) and energy-dispersive $X$-ray microanalysis were used to assess the elemental composition of the wires. They found no significant differences in $\mathrm{Ni}$ content between asretrieved and as-received wires.

Electron probe microanalysis is a standard method in the quality control of steel manufacturing. Special protocols have been developed for wavelength-dispersive spectrometry (WDS) to simultaneously obtain an element distribution map, the concentrations of the elements and a resulting phase map, as well as a volumetric estimate of all phases present ${ }^{1}$. In the field of orthodontic applications, stainless steels are predominantly analyzed with a scanning electron microscope equipped with electron detectors and a semiconductor X-ray detector ${ }^{29,30}$. In this case, the quantitative analysis is based on energydispersive spectrometry (EDS) without calibration (standardization), but with a correction procedure for atomic number ( $Z)$, absorption $(A)$, and fluorescence $(F)^{30}$. The energy resolution and the intensity ratio between line maximum (peak) and background $\left(\mathrm{I}_{\mathrm{PK}} / \mathrm{I}_{\mathrm{BG}}\right)$ is less in EDS than in 
WDS. The non-standardized ZAF-corrected EDS analysis is sufficient for a general compositional characterization of the materials. However, in more detailed studies, such as phase composition and corrosion potential, WDS of electron microprobe analysis allows lower concentrations to be analyzed and, by calibration, more reliable results for elements present in low concentration $(<0.5 \%$ by weight).

The hypothesis of this study was that there is a difference in corrosive potential in orthodontic brackets of different alloy composition and that the sensitivity of electron probe microanalysis allows detection of corrosive potential in the metal surfaces.

\section{MATERIAL AND METHODS}

In the ex-vivo/retrieval study, quantitative and qualitative analysis of two bracket systems (Nifree and Ni-containing) was performed focusing on corrosion resistance, alloy composition, and homogeneity. To compare element component alteration between the states prior to bracket bonding and after retrieval, each bracket was documented in images of secondary electrons (SE) and backscattered electrons (BSE) at low magnification. In addition, several pictures at higher magnification were obtained from selected areas.

\section{Patients}

Prior to initiation of the pilot investigation, approval was obtained from the local ethics committee of the University (IRB). All participants were patients at the department of orthodontics in need of orthodontic treatment with fixed appliances. Since all patients were adolescents, written consent to participate was obtained from both parents. Twelve patients were randomly divided into two groups (Group 1 and Group 2). Exclusion criteria were any metallic restoration or the need for additional metallic orthodontic devices such as headgear or a trans-palatal arch (TPA). The six patients in Group 1 received Ni-free brackets (Sprint-Bracket, Forestadent, Pforzheim, Germany) and the six patients in Group 2 received Ni-containing brackets (Victory Series MBT RX, 3M Unitek, Monrovia, USA).

Full arch bonding was performed in the upper and lower jaw using established bonding protocols. To isolate the effect of bracket type, the same type of orthodontic archwires were used for both groups (.014 Sentalloy, GAC International Inc., Bohemia, NY, USA). After 4 months of clinical use, the bracket of tooth 14 was removed from each patient and re-examined.

\section{Electron probe microanalysis}

Electron probe microanalysis is a destructionfree physical microanalytical method to determine the chemical composition of solid matter in high spatial resolution using detectors for electrons and for X-rays. The principle of electron probe microanalysis, as well as basic descriptions of instrumentation and technique, are summarized in Reed $^{19}$ (1997) and Potts ${ }^{7}$ (1992).

The electron probe microanalyzer (JEOL Superprobe JXA-8200, Tokyo, Japan) is equipped with an energy-dispersive system [EDS; $\mathrm{Si}(\mathrm{Li})$ ] and five wavelength-dispersive (WD) spectrometers. Two of the WD spectrometers $(\mathrm{CH}-1, \mathrm{CH}-2)$ have argonmethane gas flow counters $\left(\mathrm{Ar}: \mathrm{CH}_{4} 90 \%: 10 \%\right.$ by volume, $\mathrm{P} 10$-gas), two spectrometers $(\mathrm{CH}-3, \mathrm{CH}-4)$ have sealed xenon (Xe)-filled counters, all with a Rowland circle of $140 \mathrm{~mm}$ radius. One spectrometer $(\mathrm{CH}-5)$ is a high-resolution spectrometer with larger monochromator crystals, a sealed Xe-filled counter, and a Rowland circle with a radius of $100 \mathrm{~mm}$.

\section{Qualitative analysis}

Elements present at higher concentrations were initially detected by qualitative EDS analysis. Element distribution (intensity) maps of rectangular areas were obtained using WDS spectrometers (20 $\mathrm{kV} / 20 \mathrm{nA}$, focused beam, $5 \mu \mathrm{m}$ step width, 1000 ms dwell time). For spectrometers $\mathrm{CH}-3, \mathrm{CH}-4$, and $\mathrm{CH}-5$, the upper part of the basal plate may project into the X-ray path due to the take-off angle of $40^{\circ}$. Therefore, the mapped area had to be carefully selected to avoid absorption of the X-rays by the basal plate. Prior to the quantitative analysis, WDS scans $(20 \mathrm{kV} / 50 \mathrm{nA}, 25 \mu \mathrm{m}$ step width, $500 \mathrm{~ms}$ dwell time) were also performed over the whole accessible wavelength range to detect elements with minor concentrations. Some scans were also performed to obtain the correct spectrometer offsets to higher and lower background positions, as well as information on possible line interferences.

\section{Quantitative analysis}

For the quantitative analyses $(20 \mathrm{kV} / 20 \mathrm{nA}$, focused beam), the spectrometers (channels), selected monochromator crystals, elements, and lines were: $\mathrm{CH}-1$ PET: $\mathrm{Cr}-\mathrm{K} \alpha$; $\mathrm{CH}-2 \mathrm{TAP}$ : $\mathrm{Si}-\mathrm{K} \alpha$; CH-3 PET: Mo-L $\alpha$; CH-4 LIF: Fe-K $\alpha, \mathrm{Mn}-\mathrm{K} \alpha, \mathrm{Ni}-\mathrm{K} \alpha$, and $\mathrm{Cu}-\mathrm{K} \alpha$; and $\mathrm{CH}-5 \mathrm{LIFH}$ : Co-K $\alpha$. To get reliable counting statistics the measurement times on the peak and the two background positions were set to $20 / 10 / 10$ s for the major elements [Iron (Fe), $\mathrm{Cr}$, Ni, and Manganese (Mn)], to 30/15/15 s for Molybdenum (Mo), and to $40 / 20 / 20$ s for Silicon (Si) and Cobalt (Co). No light elements [Carbon (C), Nitrogen $\mathrm{CN}$ )] were analyzed during this preliminary study. Prior to measurement, the elements were calibrated on pure element standards. Two analysis 
routines were set up according to the alloys of the two bracket types. Both the calibration and the effect of flank or line overlap were checked by analysis of the standards using the previous analysis routines. The quantitative analysis program utilizes the CITZAF correction by Armstrong ${ }^{2}$ (1995) as implemented by the manufacturer.

\section{Sample preparation}

As electron probe microanalysis needs the analyzed surfaces to be planar and horizontally oriented, two types of specimen holders for both investigated bracket types (Figure 1) and a plate needed for guidance were custom made.

The brackets were cleaned with petroleum ether (Rotipuran, ACS, Carl Roth, Karlsruhe, Germany) to remove surface contamination. For the investigation of the original surface prior to insertion, the cleaned brackets were otherwise mounted as delivered. After recovery from the patient, the organic substances and contamination from the oral cavity deposited on the bracket surface were carefully manually removed using petroleum ether, interdental brushes, toothsticks, and cotton wool.

To obtain information on the internal fabric and to perform quantitative analysis, one additional bracket of each type was selected. The part of the basal plate projecting into the ray path was removed and a planar surface was then obtained by careful manual grinding and polishing to avoid fabric distortion.

\section{Results}

Figure 2 compares SE, BSE compositional, and BSE topographical images of one sample of both investigated bracket types at low magnification. Most brackets showed scratches resulting from clinical use (Figure 3 ). It is evident from highermagnification images (Figure 4) that both bracket types are characterized, with slight differences between the individual samples of the same type, by a surface roughness caused by steps and by linear depressions or cavities. Comparison of the same surfaces before insertion and after retrieval shows no apparent modifications in the mechanically undisturbed areas (Figures 5 and 6). In several places of the investigated bracket, and observed to a lesser degree at the other brackets, some pits appeared to have an increased size after retrieval.

Narrowly-spaced changes in composition were visible in the element distribution maps. In Group 2 , the compositional contrast between wings and brazing alloy was striking, especially for $\mathrm{Ni}$ and Si. The narrow net-like pattern that was visible in $\mathrm{BSE}, \mathrm{Cr}$, and $\mathrm{Si}$ intensity maps (Figure 7A-C) is apparently not a surface effect. In addition, several spots of brazing alloy composition were detected in SE and BSE images of the wing portion of the shown bracket (Figure 4) and were already visible by their lighter grey value in the BSE image (Figure 7A). In the Group 1 brackets, BSE images show polygonal to irregular spots of different grey values (Figure 2, Figure 7E), corresponding to two different alloy compositions with anti-correlating $\mathrm{Mn}$ and Mo concentrations. Therefore a compositionally homogenous surface was not present, and, as a

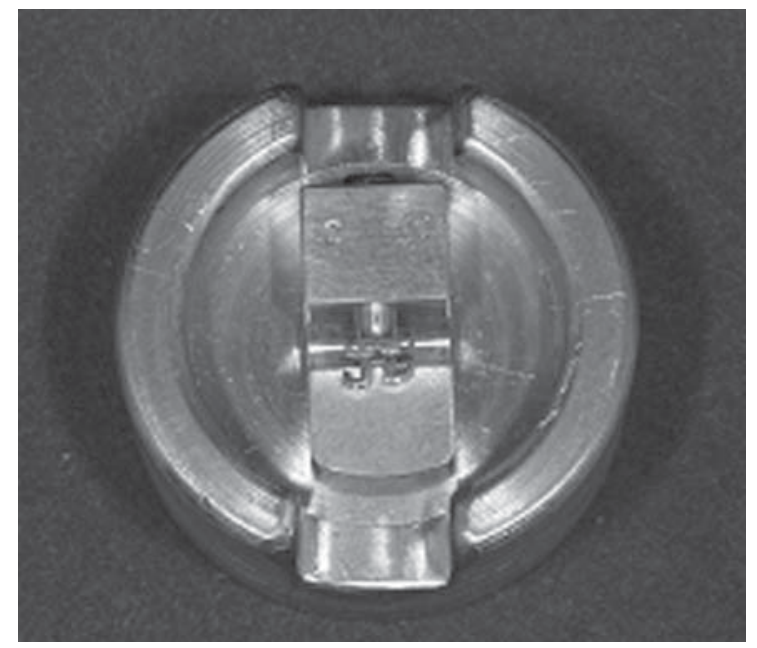

Figure 1- Specimen holder with mounted bracket in holder block

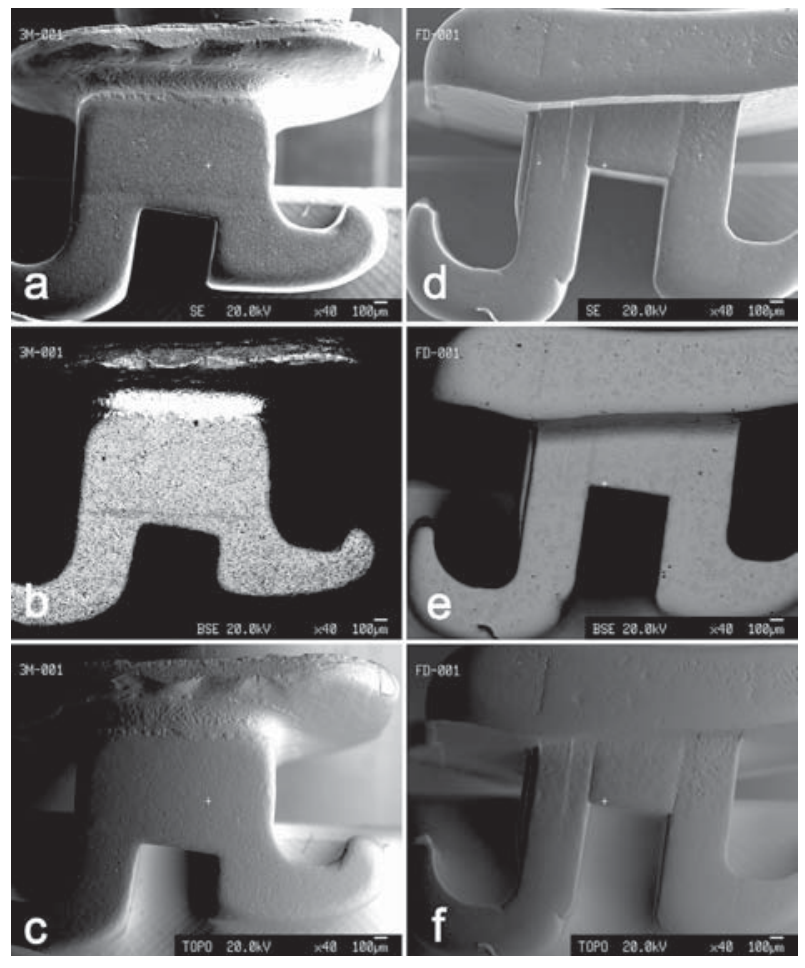

Figure 2- Overview images of two brackets, as delivered and after cleaning with petroleum ether. (a-c) Group 1; (df) Group 2. Images: (a, d) secondary electron (SE), back scattered electron in (b, e) compositional mode (BSE), and in (c, f) topographic mode (TOPO) 


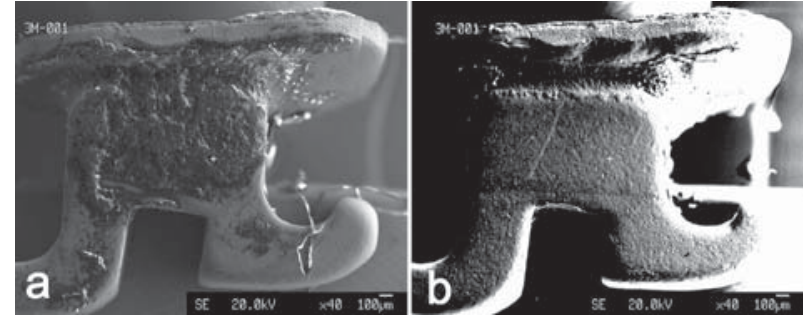

Figure 3- Overview secondary electron (SE) images of Group 1 brackets, after recovery from patients (a) with dried plaque and (b) after cleaning

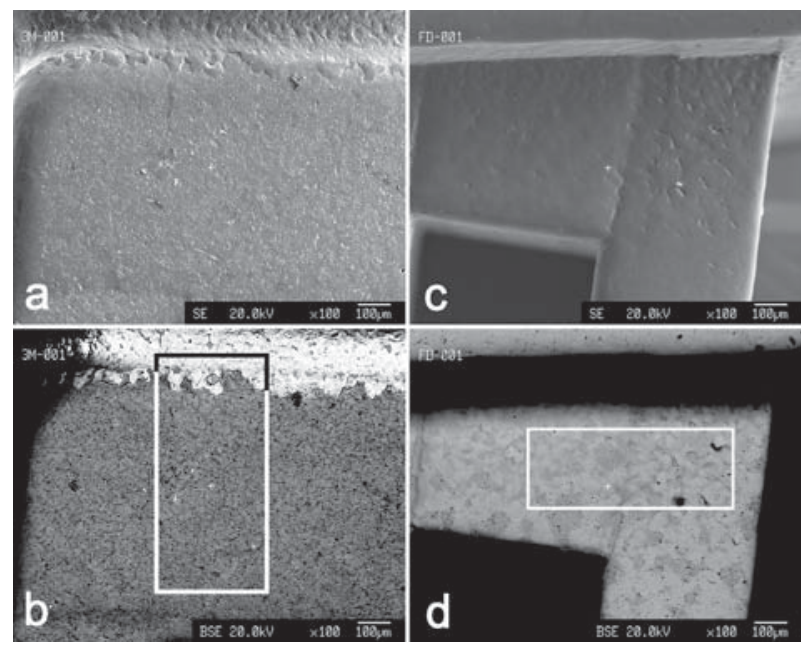

Figure 4-Surface details of brackets at larger magnification displaying the rough surface of the wing section. $(a-b)$ Group 1; (c-d) Group 2. Images: (a, c) secondary electron (SE), (b, d) back scattered electron in compositional mode (BSE) In BSE images the rectangles mark the position of the element distribution maps: (b) Group 1 (H $350 \mu \mathrm{m}, \mathrm{V}$ $750 \mu \mathrm{m})$, (d) Group 2 (H $650 \mu \mathrm{m}, \mathrm{V} 250 \mu \mathrm{m})$. The size and orientation of the element distribution maps is confined by the geometry of the bracket, especially the part of the basal plate projecting into the ray path between excitation volume and spectrometers

consequence, there is potential for corrosion.

Quantitative analysis showed that two different steels were used for the base and wings of the group 2 brackets. Nearly all the material of the base consisted of $\mathrm{Cr}$ - and $\mathrm{Ni}$-rich steel, with minor amounts of Mo and copper ( $\mathrm{Cu}$ ) (Table 1, analysis 1). A relatively $\mathrm{Cr}$ - and Mo-rich, Ni-poor material was present in very small quantity and confined to grain boundaries (Table 1 , analysis 2 ). The wings consisted of a steel lower in $\mathrm{Cr}, \mathrm{Mn}, \mathrm{Mo}$, and $\mathrm{Ni}$, but considerably higher in $\mathrm{Cu}$ (Table 1, analysis 4). Generally, the steel of the basal plate was similar to 1.4550 (SST-347, UNS S 34700, X6 CrNiNb 18 10), except for the presence of Mo and the lack of detectable Niobium ( $\mathrm{Nb})$. The steel of the wings resembled 1.4542 (17-4PH; X5CrNiCuNb16-4), except that $\mathrm{Nb}$ and Tantalum ( $\mathrm{Ta}$ ) were not detected during our study. One composition of the brazing

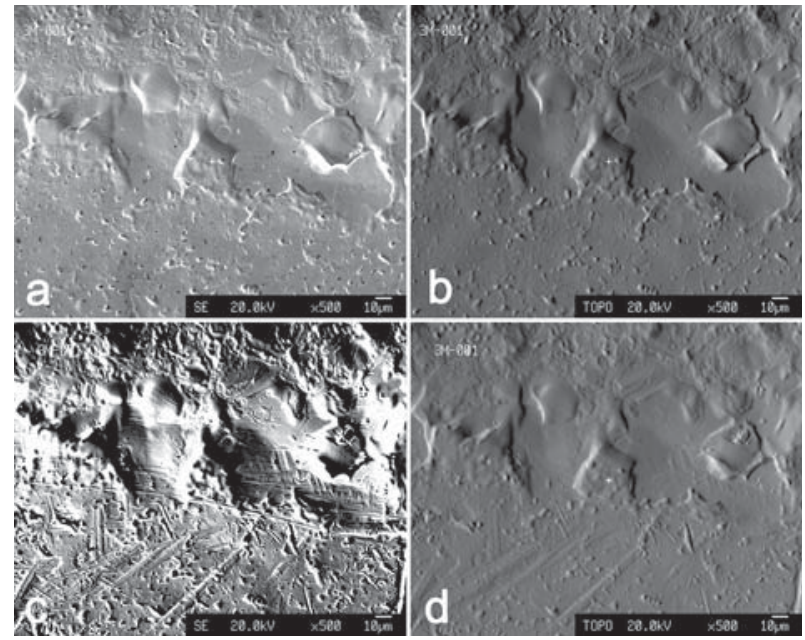

Figure 5- Detailed secondary electron (SE) and back scattered electron in topographic mode (BSE-TOPO) images of characteristic features before insertion (a-b) and after recovery and cleaning (c-d) of a Group 1 bracket. Besides the obvious scratches present in the wing portion after recovery, cavities in mechanically untreated areas show no detectable change. In the brazing alloy part, a few minor changes are visible at the right-hand side of the image, very likely due to mechanical treatment during retrieval

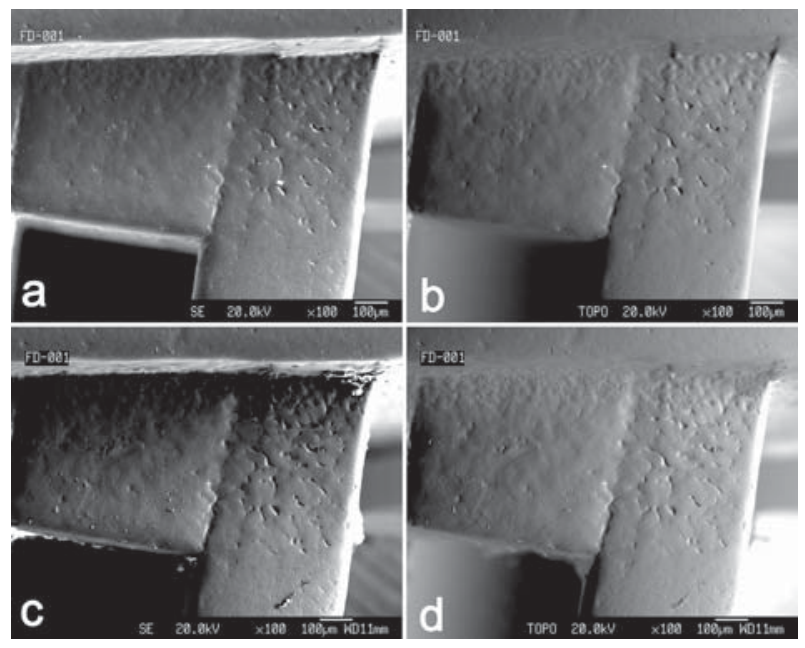

Figure 6- Detailed secondary electron (SE) and back scattered electron in topographic mode (BSE-TOPO) images of characteristic features before insertion (ab) and after recovery and cleaning (c-d) of a Group 2 bracket. After recovery, cavities in mechanically untreated areas show no detectable change

alloy in the center of a larger area of the filler (Table 1 , analysis 3 ) shows a Si- and Ni-rich composition. Some adjacent material was analyzed due to the small size of the grain, but the composition tends towards the one given by Zinelis, et al. ${ }^{29}$ (2004) for the braze alloy of Gemini brackets (3M Unitek).

The group 1 bracket consists of a virtually $\mathrm{Ni}$ free high-N austenitic steel (X15 CrMnMoN 1711 
3) named P.A.N.A.C.E.A. (Protection Against Ni Allergy, Corrosion, Erosion and Abrasion) developed at the Institute of Metallurgy, ETH Zürich ${ }^{27}$. The compositional range is given (in weight percentages)

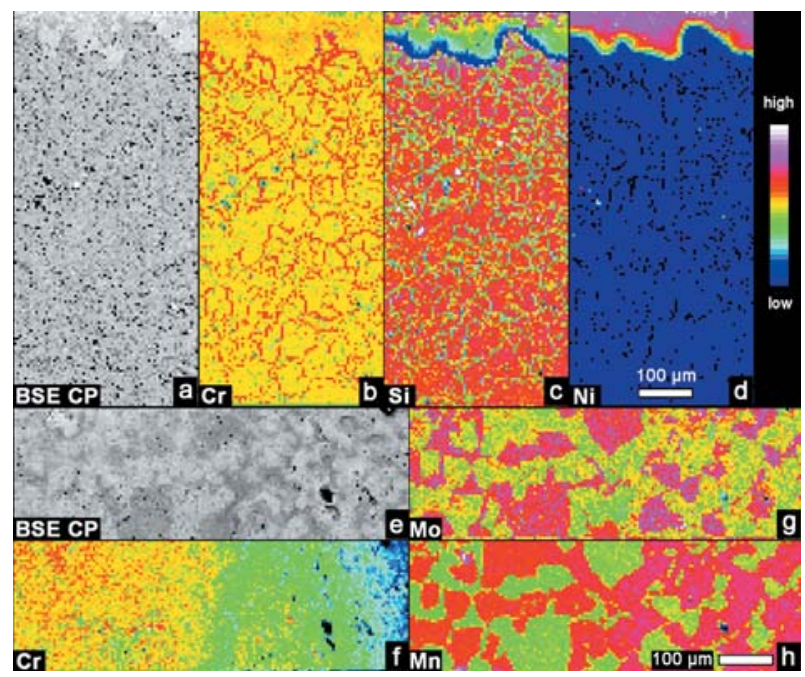

Figure 7- Back scattered electron (BSE) image and enhanced element distribution (intensity) maps of two investigated brackets: (a-d) Group 1 series, (e-h) Group 2 series. The grey value in BSE CP (compositional) images corresponds to a difference in mean atomic number (compare to Figures $4 \mathrm{~b}, \mathrm{~d}$ ). In the element distribution maps, the intensities, and thus the relative concentrations, are colour-coded; colour scale from low intensity (blue) to high intensity (white). In (c), showing the concentration of $\mathrm{Si}$, two maps were combined due to very different $\mathrm{Si}$ concentrations in steel and brazing alloy. Note in group 1 series the sharp contrasts in composition between brazing alloy and wing (b-d) and in group 2 series the juxtaposed areas of differing composition (f-h). In (f), the intensity gradient is the result of a slightly inclined sample surface causing the excitation volume to move out of the spectrometer focus

Table 1- Chemical composition of brackets (wt.-\%) as $\mathrm{Cr}$ 16.5-17.5\%, Mo 3.0-3.5\%, Mn 10-12\%, N 0.6-1.2\%, Fe balance ${ }^{13}$, or as Cr 15-18\%, Mo 3-6\%, $\mathrm{Mn} 10-12 \%$, N 0.9\%, Fe balance 27 , the average values as $\mathrm{Cr} 17.3 \%$. Mo 3.2\%, $\mathrm{Ni}<0.05 \%$, Mn $12 \%$, $\mathrm{N} 0.9 \%$, balance $\mathrm{Fe}^{22}$. When properly processed the steel is fully austenitic 22 .

\section{DISCUSSION}

Both working hypotheses, that varying orthodontic brackets have alloys with different corrosive potentials, and that the sensitivity of the electron probe microanalysis is an adequate measure to detect small changes in element composition, were accepted. Investigation of six $\mathrm{Ni}$-free brackets and six $\mathrm{Ni}$-containing brackets revealed that corrosion potential exists due to surface morphology and the juxtaposition of materials of different composition. The use of three different materials for the $\mathrm{Ni}$-containing brackets (i.e. basal plate and wings joined by a brazing alloy) yields sharp edges where the brazing alloy projects over the other parts.

The observation that some pits appeared to have increased in size after retrieval cannot be attributed to corrosion phenomena, as mechanical treatment during the period of wear or during retrieval cannot be excluded. Major concerns pertaining to the biocompatibility, potential hypersensitivity, and corrosion resistance of metallic orthodontic devices could not be proven or disproven due to the pilot character of the investigation, but results clearly underscore an obvious corrosion potential in the examined specimens ${ }^{5,21}$. Scientific data on corrosion potential in orthodontic devices is contradictory. A previous in vitro investigation ${ }^{5}$ found that while none of the tested orthodontic wires and brackets was susceptible to pitting corrosion, galvanic corrosion was measurable after 28 days of exposure in lactic acid solution. Siargos, et al. ${ }^{21}$ (2007)

\begin{tabular}{|c|c|c|c|c|c|c|c|c|c|c|}
\hline Element & $\mathrm{Cr}$ & $\mathrm{Si}$ & Mo & $\mathrm{Mn}$ & $\mathrm{Fe}$ & Co & $\mathrm{Ni}$ & $\mathrm{Cu}$ & Total & Comment \\
\hline \multicolumn{11}{|c|}{$\begin{array}{c}\text { Group } 2 \\
\text { (Ni containing) }\end{array}$} \\
\hline 1 & 18,700 & 0.415 & 0.496 & 2,000 & 68,100 & 0,000 & 9,810 & 0.338 & 99,920 & base, light grey \\
\hline 2 & 26,700 & 0.448 & 0.866 & 1,650 & 65,100 & 0,000 & 4,610 & 0.197 & 99,590 & $\begin{array}{l}\text { base, dark } \\
\text { grey }\end{array}$ \\
\hline 3 & 9,860 & 13,100 & 0.041 & 5,070 & 7,380 & 0,000 & 62,000 & 1,040 & 98,540 & brazing alloy \\
\hline 4 & 16,100 & 0.363 & 0.133 & 0.671 & 75,400 & 0,000 & 3,950 & 3,050 & 99,670 & wing \\
\hline \multicolumn{11}{|c|}{ Group 1 (Ni-free) } \\
\hline 5 & 17,500 & 0.663 & 3,110 & 11,100 & 67,500 & 0.072 & 0.069 & 0,000 & 100,020 & core \\
\hline 6 & 17,300 & 0.798 & 4,590 & 9,950 & 67,300 & 0.065 & 0.064 & 0,000 & 100,080 & rim \\
\hline 7 & 17,100 & 1,020 & 6,900 & 8,750 & 66,400 & 0.065 & 0.055 & 0,000 & 100,310 & $\begin{array}{c}\text { phase, light } \\
\text { grey }\end{array}$ \\
\hline
\end{tabular}


compared conventional and metal injection molded brackets with commonly used orthodontic archwires and found comparable potential differences for both bracket types. The detected steps and linear depressions or cavities can be considered additional primary loci for corrosion, especially as such voids provide spaces for microbial plaque that cannot be easily removed by conventional tooth cleaning procedures. The same is true for the observed areas of brazing alloy composition in Group 2 that most likely resemble material sputtered onto the wing during the procedure of joining the basal plate and the wing, thus producing local areas with greater potential for corrosion by half cell generation. Additionally, as shown by Siargos, et al. ${ }^{21}$ (2007), the heterogeneous material composition, manufacturing processes, and microstructure of brackets have an immediate influence on the corrosion potential, and the galvanic susceptibility might be triggered by applying different archwires.

Organic substances and contamination deposited on the bracket surface had to be removed prior to the re-assessment of the retrieved brackets. This phenomenon of a protective passive film on $\mathrm{Fe}-\mathrm{Cr}$ $\mathrm{Ni}$-based stainless steel alloys composed of $\mathrm{Cr}_{2} \mathrm{O}_{3}$ is well known. In an investigation by Lin, et al.14 (2006) a variation in the corrosion resistance of different stainless steel brackets is clearly shown, even though they all had an identical passive film structure. In the oral cavity, this passive film is susceptible to mechanical and chemical factors (e.g. carbonate drinks or fluoride containing products). An increase of corrosion susceptibility caused by toothpastes and mouthwashes containing fluoride has also been shown in in vitro investigations ${ }^{20,25}$ which demonstrated the destruction of the oxide layer. In an in vivo split mouth study, Harzer, et al. ${ }^{10}$ (2001) investigated the sensitivity of titanium and stainless steel brackets to fluoride toothpaste and tea. They found no significant differences, which is contrary to the findings of other studies but can probably be explained by the short exposure time. This phenomenon has an immediate effect on orthodontic treatment. Corrosion of the bracket or wire surface leads to surface roughening and a resultant increase of adhering hard tartar. As a consequence, control of orthodontic forces may become unpredictable.

The increasing availability and application of different materials for orthodontic treatment, coupled with the complexity of the oral environment, indicate a need for further investigations on the biocompatibility of metallic materials to ensure patient health.

\section{CONCLUSION}

Electron probe microanalysis is a valuable tool for the characterization of element distribution and quantitative analysis for corrosion studies. The duration and intensity of the exposure of the brackets to saliva and food were not sufficient to produce corrosion observable with SE or BSE. Future studies employing larger sample sizes and longer periods of clinical use will provide important information on the local behavior of orthodontic devices.

\section{REFERENCES}

1- Angeli J, Haselgrubler K, Achammer EM, Burger H. Surface analysis of steel sheets with GDOS and EPMA. Fresenius J Anal Chem. 1993;346:138-43.

2- Armstrong JT. CITZAF: a package of correction programs for the quantitative electron microbeam X-ray analysis of thick polished materials, thin films, and particles. Microbeam Analysis. $1995 ; 4: 177-200$.

3- Barrett RD, Bishara SE, Quinn JK. Biodegradation of orthodontic appliances. Part I. Biodegradation of nickel and chromium in vitro. Am J Orthod Dentofacial Orthop. 1993;103:8-14.

4- Ccahuana VZ, Ozcan M, Mesquita AM, Nishioka RS, Kimpara ET, Bottino MA. Surface degradation of glass ceramics after exposure to acidulated phosphate fluoride. J Appl Oral Sci. 2010;18:155-65. 5- Darabara MS, Bourithis LI, Zinelis S, Papadimitriou GD. Metallurgical characterization, galvanic corrosion, and ionic release of orthodontic brackets coupled with $\mathrm{Ni}-\mathrm{Ti}$ archwires. J Biomed Mater Res B Appl Biomater. 2007;81:126-34.

6- Eliades T, Athanasiou AE. In vivo aging of orthodontic alloys: implications for corrosion potential, nickel release, and biocompatibility. Angle Orthod. 2002;72:222-37.

7- Eliades T, Zinelis S, Papadopoulos MA, Eliades G, Athanasiou $\mathrm{AE}$. Nickel content of as-received and retrieved $\mathrm{NiTi}$ and stainless steel archwires: assessing the nickel release hypothesis. Angle Orthod. 2004;74:151-4.

8- Geurtsen W. Biocompatibility of dental casting alloys. Crit Rev Oral Biol Med. 2002;13:71-84.

9- Haddad AC, Tortamano A, Souza AL, Oliveira PV. An in vitro comparison of nickel and chromium release from brackets. Braz Oral Res. 2009;23:399-406.

10- Harzer W, Schröter A, Gedrange T, Muschter F. Sensitivity of titanium brackets to the corrosive influence of fluoride-containing toothpaste and tea. Angle Orthod. 2001;71:318-23.

11- House K, Sernetz F, Dymock D, Sandy JR, Ireland AJ. Corrosion of orthodontic appliances - should we care? Am J Orthod Dentofac Orthop. 2008;133:584-92.

12- Janson GR, Dainesi EA, Consolaro A, Woodside DG, Freitas MR. Nickel hypersensitivity reaction before, during, and after orthodontic therapy. Am J Orthod Dentofacial Orthop. 1998; 113:655-60.

13- Kim SJ, Bae SN, Kim JH, Kim CT, Han KT, Lee JM, et al. P.A.N.A.C.E.A. provides the answer to $\mathrm{Ni}$ allergy. Metal Powder Report. 1998;53:50-2.

14- Lin MC, Lin SC, Lee TH, Huang HH. Surface analysis and corrosion resistance of different stainless steel orthodontic brackets in artificial saliva. Angle Orthod. 2006;76:322-9.

15- Noble J, Ahing SI, Karaiskos NE, Wiltshire WA. Nickel allergy and orthodontics, a review and report of two cases. Br Dent J. 2008;204;297-300.

16- Pantuzo MC, Zenóbio EG, Andrade Marigo H, Zenóbio MA. Hypersensitivity to conventional and to nickel-free orthodontic brackets. Braz Oral Res. 2007;21:298-302. 
17- Potts PJ. A handbook of silicate rock analysis. Glasgow: Blackie Academic \& Professional (Chapman \& Hall); 1992.

18- Powers JM, Sakaguchi RL. Craig 's restorative Dental Materials. $12^{\text {th }}$ ed. St. Louis: Mosby; 2006.

19- Reed SJB. Electron microprobe analysis. $2^{\text {nd }}$ ed. Cambridge: Cambridge University Press; 1997

20- Schiff N, Dalard F, Lissac M, Morgon L, Grosgogeat B. Corrosion resistance on three orthodontic brackets: a comparative study of three fluoride mouthwashes. Eur J Orthod. 2005;27:541-9.

21- Siargos B, Bradley TG, Darabara M, Papadimitriou G, Zinelis S. Galvanic corrosion of metal injection molded (MIM) and conventional brackets with nickel-titanium and copper-nickeltitanium archwires. Angle Orthod. 2007;77:355-60.

22- Speidel MO, Uggowitzer PJ. Biocompatible nickel-free stainless steel to avoid nickel allergy. In: Speidel MO Uggowitzer $\mathrm{P}$, eds. Materials in Medicine. Zürich: VDF Hochschulverlag; 1998. p.191-208.

23- Staerkjaer L, Menné T. Nickel allergy and orthodontic treatment. Eur J Orthod. 1990;12:284-9.

24- Tomakidi $P$, Koke $U$, Kern R, Erdinger $L$, Krüger $H$, Kohl A, et al. Assessment of acute cyto- and genotoxicity of corrosion eluates obtained from orthodontic materials using monolayer cultures of immortalized human gingival keratinocytes. J Orofac Orthop. 2000;61:2-19.
25- Toniollo MB, Tiossi R, Macedo AP, Rodrigues RC, Ribeiro RF, Mattos MG. Effect of fluoride-containing solutions on the surface of cast commercially pure titanium. Braz Dent J. 2009;20:201-4. 26- Tuna SH, Pekmez NO, Keyf F, Canli F. The electrochemical properties of four dental casting suprastructure alloys coupled with titanium implants. J Appl Oral Sci. 2009;17:467-75.

27- Uggowitzer PJ, Magdowski R, Speidel MO. Nickel free high nitrogen austenitic steels. ISIJ Int. 1996;36:901-8.

28- Wataha JC, Lockwood PE, Messer RL, Lewis JB, Mettenburg DJ. Brushing-induced surface roughness of nickel-, palladium-, and gold-based dental casting alloys. J Prosthet Dent. 2008;99:45560.

29- Zinelis S, Annousaki O, Eliades T, Makou M. Elemental composition of brazing alloys in metallic orthodontic brackets. Angle Orthod. 2004;74:394-9.

30- Zinelis S, Annousaki O, Makou M, Eliades T. Metallurgical characterization of orthodontic brackets produced by metal injection molding (MIM). Angle Orthod. 2005;75:1024-31. 